\title{
Eugenol oil nanoemulsion: antifungal activity against Fusarium oxysporum f. sp. vasinfectum and phytotoxicity on cottonseeds
}

\author{
Kamel A. Abd-Elsalam • Alexei R. Khokhlov
}

Received: 10 December 2014/ Accepted: 27 December 2014/Published online: 10 January 2015

(C) The Author(s) 2015. This article is published with open access at Springerlink.com

\begin{abstract}
The current research deals with the formulation and characterization of bio-based oil-in-water nanoemulsion. The formulated eugenol oil nanoemulsion was characterized by dynamic light scattering, stability test, transmission electron microscopy and thin layer chromatography. The nanoemulsion droplets were found to have a Z-average diameter of $80 \mathrm{~nm}$ and TEM study reveals the spherical shape of eugenol oil nanoemulsion (EON). The size of the nanoemulsion was found to be physically stable up to more than 1-month when it was kept at room temperature $\left(25^{\circ} \mathrm{C}\right)$. The TEM micrograph showed that the EON was spherical in shape and moderately mono or di-dispersed and was in the range of 50-110 $\mathrm{nm}$. Three concentrations of the nanoformulation were used to evalute the anti-fusarium activity both in vitro and in vivo experiments. SDS-PAGE results of total protein from the Fusarium oxysporum f. sp. vasinfectum (FOV) isolate before and after treatment with eugenol oil nanoemulsion indicate that the content of extra cellular soluble small molecular proteins decreased significantly in EON-treated fungus. Light micrographs of mycelia and spores treated with EON showed the disruption of the fungal structures. The analysis of variance (ANOVA) for Fusarium wilt incidence indicated highly significant $(p=0.000)$
\end{abstract}

K. A. Abd-Elsalam ( $\square)$

Plant Pathology Research Institute, Agricultural Research

Centre, Giza, Egypt

e-mail: kamelabdelsalam@gmail.com;

abd-elsalam.k.a@post.com

K. A. Abd-Elsalam

Unit of Excellence in Nano-Molecular Plant Pathology

Research, Giza, Egypt

A. R. Khokhlov

A.N. Nesmeynov Institute of Organoelement Compounds

(INEOS) of Russian Academy of Sciences, Moscow, Russia effects of concentration, genotype, and their interaction. The difference in wilt incidence between concentrations and control was not the same for each genotype, that is, the genotypes responded differently to concentrations. Effects of three EON concentration on germination percentage, and radicle length, were determined in the laboratory. One very interesting finding in the current study is that cotton genotypes was the most important factors in determining wilt incidence as it accounted for $93.18 \%$ of the explained (model) variation. In vitro experiments were conducted to evaluate the potential phytotoxic effect of three EON concentrations. Concentration, genotype and concentration $\mathrm{x}$ genotype interaction were all highly significant sources of variation in seed germination; however, interaction was the first in importance as a source of variation followed by the concentration, while genotype was the least important source of variation. These results suggest the potential use of eugenol oil nanoemulsion for protecting seedcotton from Fusarium wilt infection.

Keywords Essential oils - Nanoencapsulation · Phytotoxicity · SDS-PAGE · Fusarium wilt

\section{Introduction}

Fusarium oxysporum f. sp. vasinfectum causes important crop losses in the most cotton-producing countries. Fusarium wilt is a destructive disease of cotton (Gossypium spp.) in several countries of the globe including Australia, USA, Egypt, Tanzania, and China (Watkins 1981; Hillocks 1992; Abd-Elsalam et al. 2014). The first recorded of this disease outside the USA came from Egypt, where it was quickly disseminated after the release of the highly susceptible cultivar 'Sakal' during 
the 1920s (Fahmy 1927). Currently, selection and breeding of new genotypes with higher levels of resistance to fusarium wilt are the main approaches to control this disease (Abd-Elsalam et al. 2014). The improvement of cotton cultivar resistance through conventional plant breeding methods is time-consuming and laborious (Tohidfar et al. 2012).

Long-term extensive fungicides in open field have led to the appearance of fungicide-resistant populations of fungal pathogens (Brent and Hollomon 1998). Overall, intensive fungicide application results in several negative effects in the environment that cannot be ignored (Feng and Zheng 2007). Therefore, development of alternative eco-safe antifungal agents like bio-based nanomaterials is urgently needed. A number of nanotechnologies can improve the current crop management protocols within a short term (Pérez-de-Luque and Rubiales 2009; AbdElsalam 2012; Kah et al. 2013). Recently, nanomaterials (particle size $<100 \mathrm{~nm}$ ) are being developed and offer the opportunity to more efficiently and safely administration of pesticides, fungicides, herbicides, and fertilizers by better delivery of active ingredients, and less environmental drift (Li et al. 2007; Gogoi et al. 2009). Antimicrobial nanoemulsions are highly stable oil-inwater emulsions composed of nanometer-sized, positively charged droplets that have broad-spectrum activity against enveloped viruses, fungi, and bacteria (Hamouda et al. 2001; Myc et al. 2002; Wang et al. 2007). Nanobiocide a product prepared by mixing several bio-based chemicals was reported to eliminate fungus Magnaporthe grisea, the causal agent of rice blast disease (Gogoi et al. 2009). Clove and eugenol oil showed good potential to inhibit growth of A. niger, Penicillium sp., and Rhizopus sp. on media. Eugenol, a main component of clove oil, was proposed as the agent responsible for clove oil's antifungal activity against a wide range of plant pathogens (Pinto et al. 2009; Wang et al. 2010; Matan et al. 2011; Ghosh et al. 2014). Therefore, the present study was aimed to formulate and characterize the eugenol oil nanoemulsion using non-ionic surfactant Tween 20 with water as a continuous aqueous phase. The antifungal activities of the synthesized EONs was evaluated in vitro and in vivo. SDS-PAGE analysis of FOV treated by EON was studied to determine the mode of action of EON. One of the most important issues to be addressed before the extensive utilization of nanomaterials is the evolution of their possible toxicity. Thus, the phytotoxicity effects of EON on cotton genotypes were assessed.

\section{Materials and methods}

Pseudo-ternary phase diagram

Mean droplet size of each prepared composition was completed to verify nanoemulsion region using pseudoternary phase diagram. Every corner correspond to $100 \%$ of water, surfactants (Tween) and oil. Phase diagrams were created using TRIANGULAR software.

Preparation of the nanoformulations

Commercial products of eugenol oil were used in the present study. Eugenol (C10H12O2), a phenylpropanoid, is an allyl chain-substituted guaiacol. The eugenol oil (>99 \%, MW164.21; Fluka code 46100), and non-ionic surfactant (Tween 20) were added slowly under gentle stirring until a homogeneous mixture formed. Then water was added drop wise at $37{ }^{\circ} \mathrm{C}$ and stirred at $43 \mathrm{~g}$. This mixture was sonicated using an Ultrasonicator (Bandelin SONOPULS HD 2200, Germany) for $10 \mathrm{~min}$ at $700 \mathrm{~W}$. The particle size and shape of $10 \%$ eugenol nanoemulsion were detected by stability measurement, particle size analyzer and transmission electron microscope.

Stability of nanoemulsion

The stability analysis was performed by centrifuging the $10 \%$ eugenol nanoemulsion at $3,500 \mathrm{rpm}$ for $30 \mathrm{~min}$ (Shafiq and Shakeel 2010). The stability was further checked at both refrigerator temperature $\left(4^{\circ} \mathrm{C}\right)$ and room temperature $\left(25^{\circ} \mathrm{C}\right)$. Three freeze-thaw cycles between $21{ }^{\circ} \mathrm{C}$ and $+25{ }^{\circ} \mathrm{C}$ were also checked. Stability assay was also performed by storage for 3 months. Ten percent of eugenol nanoemulsion was diluted to 1,2 , and $5 \%$ eugenol nanoemulsion solution by distilled water and store at RT until usage. The purpose of these tests was to select a stable, low-surfactant formulation with a nanoemulsionsize droplet and stable physicochemical properties.

Measurement of nanoemulsion droplet size

Measurement of droplet size of nanoemulsion was performed by a dynamic light scattering method using Zetasizer Nano ZS (Malvern Instruments, UK) at room temperature. Prior to measurement, $30 \mu \mathrm{l}$ of the nanoemulsion was diluted with $3 \mathrm{ml}$ of water at $25{ }^{\circ} \mathrm{C}$. Particle size data were expressed as the mean of the Z-average of 3 independent batches of the nanoemulsions. 
Transmission electron microscopy (TEM)

Twenty microliters of diluted samples was placed on a film-coated 200-mesh copper specimen grid for $10 \mathrm{~min}$ and the fluid excess was eliminated using filter paper. The grid was then stained with one drop of $3 \%$ phosphotungstic acid and allowed to dry for $3 \mathrm{~min}$. The coated grid was dried and examined under the TEM microscope (Philips, $\mathrm{CM}$ 12). The samples were observed by operating at $120 \mathrm{kV}$.

Analysis of column fractions through TLC

Three eugenol nanoemulsion concentration and reference standards were dissolved in ethyl acetate $(10 \mu \mathrm{l} / \mathrm{mL})$ and $8 \mu \mathrm{l}$ of each from oils and standards was inoculated in two TLC plates coated with silica gel $(20 \times 20 \mathrm{~cm}$ TLC silica gel 60-F254 aluminum sheet, Merck, Germany) by Hamilton syringe (Germany). When the solvent phase reached the top, the plate was air dried and TLC plates were examined under UV light $(254 \mathrm{~nm})$ and followed by dipping in alcoholic vanillin sulfuric acid reagent (Hostettmann 1999). The plate was then taken out and photographed using a Gel Documentation System (UV Tech, UK).

\section{Antifungal assay}

In vitro antifungal activity of prepared EON was determined by measuring the growth inhibition of FOV through agar well diffusion assay (Perez et al. 1990). Wells of $5 \mathrm{~mm}$ diameter were punched in the petri dishes, $30 \mu \mathrm{l}$ of the EON was divided and dropped in each the well. Plates were inoculated with FOV mycelial disc $(4 \mathrm{~mm})$. The petriplates were kept in refrigerator at $4{ }^{\circ} \mathrm{C}$ for $3 \mathrm{~h}$, to allow EO to diffuse into the agar medium. The control will be performed with the medium without the addition of EON. Plates were incubated at $28 \pm 1{ }^{\circ} \mathrm{C}$ for $72 \mathrm{~h}$ in incubator and the presence of a zone of inhibition $(\mathrm{cm})$ surrounding the two well was measured (Daferera et al. 2003).

\section{Fungal morphological study}

This assay enables the observation of possible morphological changes displayed by the fungus when it was exposed to EON antifungal activity. Conidia and mycelia from FOV were incubated for $48 \mathrm{~h}$ in the presence of EON at the concentration of 1 and $2 \%$. The control plates without EON were also stained and their morphological features were observed. Samples were fixed in safranin stain. Morphological changes were examined by light microscope. Each assay was repeated at least three times.

\section{Protein analysis}

SDS-PAGE was performed by the method described by Laemmli (1970). Proteins were analyzed on $1.5-\mathrm{mm}$ thick and $15-\mathrm{cm}$ long gels run in a dual vertical slab unit (Hoefer Scientific Instruments, San Francisco, CA, USA). From each sample, $25 \mu$ l of protein extract was loaded on a polyacrylamide gel. The separation gel $(10 \%)$ and staking gel $(3.5 \%)$ were prepared from an acrylamide monomer solution (Roth, Karlsruhe, Germany). Protein was electrophoresed at a constant current of $30 \mathrm{~mA}$ through the stacking gel, and at $90 \mathrm{~mA}$ through the separation gel at room temperature, the gels were stained by silver nitrate (Rabilloud et al. 1988).

Effect of seed dressing treatment with EON on Fusarium wilt incidence

Ten genotypes supplied by cotton breeders were screened for Fusarium wilt incidence under greenhouse conditions using soil infested with highly virulent FOV isolates. Fifty seeds were surface sterilized by gently shaking in $1 \%$ $\mathrm{NaOCl}$ solution for $3 \mathrm{~min}$ and rinsed six times for $5 \mathrm{~min}$ in sterile deionized water. Seeds were soaked in 1, 2, and $5 \%$ eugenol nanoemulsion for about $30 \mathrm{~min}$. Infested soil was dispensed in $15 \mathrm{~cm}$ diameter clay pots and each pot was planted with 10 seeds. Pots were distributed on greenhouse benches in a randomized complete block design. The greenhouse was equipped with a heating system assuring that the minimum temperature in the greenhouse was maintained at $28{ }^{\circ} \mathrm{C}$. The test was repeated once with almost the same results. Percentage of infected seedlings was recorded 45 days from sowing.

\section{Effect of seed treatment with EON viability} of cottonseeds

Three concentrations $(1,2$, and $5 \%)$ of EON were tested as to their effects on cottonseed germination percentage and radicle length in vitro. Assays were performed according to ISTA protocol with slight modification [26] (Anonymous $2000)$ in $12 \times 12 \times 1.5 \mathrm{~cm}$ plastic dishes on 2 layers of filter paper. After moistening the paper with sterile distilled water, 10 seeds were placed in each dish.

The dishes were incubated in an illuminated room $(6,000 \mathrm{~lx}, 12 / 12 \mathrm{~h}$ day/night $)$ at $20^{\circ} \mathrm{C}$. The final percentage germination and radicle length $(\mathrm{cm})$ were recorded after 7 days from planting on filter paper. Radicle length was measured from tip of primary root to the base of hypocotyls. The experiment was repeated twice. 
Statistical analyses

The experimental design of the present study was randomized complete block with three replications in the greenhouse test and with five replications in the laboratory test. Data were subjected to analysis of variance (ANOVA). Least Significant Difference (LSD) was used to compare concentration means within genotypes. ANOVA was performed with MSTAT-C statistical package. The experiments were duplicated.

\section{Results}

Phase diagram of nanoemulsions

A pseudo-ternary phase diagram was constructed to identify the formation of nanoemulsion. A total of 4 emulsions were prepared using diverse percentages of water, eugenol oil and tween 20 as a fellow: (5\% of oil, $5 \%$ of tween 20 , $90 \%$ of water), (7.5\% of oil, $10 \%$ of tween $20,82 \%$ of water), (10\% of oil, $15 \%$ of tween $20,75 \%$ of water) and (12.5\% of oil, $17.5 \%$ of tween $20,70 \%$ of water). Nanoemulsion systems are mixtures of oils, surfactants, and water, which can produce nanoemulsions with a particle size bellow $100 \mathrm{~nm}$, ranging from 50 to $120 \mathrm{~nm}$ and are clear and transparent (Fig. 1). Only the nanoemulsion regions were plotted in the pseudo-ternary phase diagram (Fig. 2).

\section{Stability studies}

The size of the nanoemulsion was found to be physically stable after centrifugation at $10,000 \mathrm{~g}$ for $30 \mathrm{~min}$ up to more 1-month kept at room temperature. Nanoemulsions are kinetically stable systems and are formed from a particular concentration of oil phase, surfactant and water, with no phase separation. This shows that the formulated nanoemulsion survived the stability tests. Eugenol emulsion before subjecting to ultrasonic emulsification

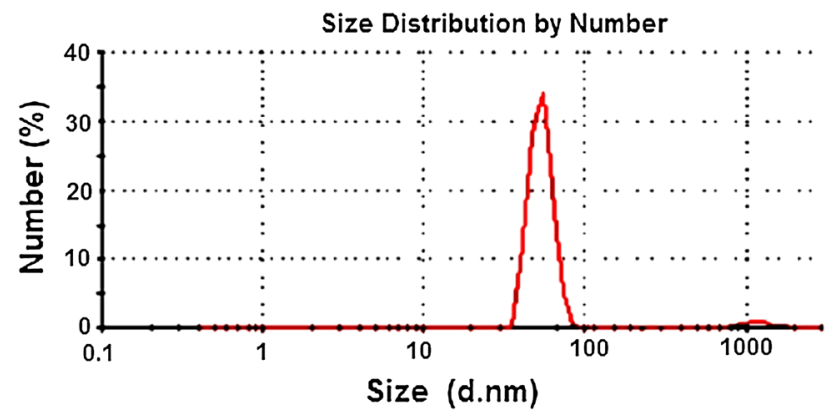

Fig. 1 Droplet size distribution of nanoemulsions after $24 \mathrm{~h}$ comprised of droplets in macro and micrometer range (Fig. 3a, b). While, Tween 20-based eugenol oil nanoemulsion formulation was turbid and milky white in color (Fig. 3c).

\section{Transmission electron microscopy (TEM)}

Transmission electron microscopy characterization of EON gives the actual size and shape; the droplets in the nanoemulsion appear dark. The TEM micrograph showed that the EON was spherical in shape and moderately mono or di-dispersed and was in the range of 50-110 nm (Fig. 4). The droplet size was correlated well with the results obtained from droplet size analysis using the dynamic light scattering.

Chromatographic identification of eugenol

TLC results of column fractions (Lanes 1-3) along with eugenol standard (Lane $S$ ) are shown in Fig. 5. A dark purple band with a retention factor $\left(\mathrm{R}_{\mathrm{f}}\right)$ value of 0.81 was identified as eugenol in comparison with standard eugenol that had the same $R_{f}$ value. The result of antifungal assay of column fractions and that of TLC confirms that the antifungal activity is eugenol content.

\section{In vitro evaluation of antifungal activity}

According to disc diffusion assay, the antifungal activity in terms of zone of inhibition of three EON concentration was tested against four FOV isolates. The EON exhibited varying antifungal activity against the various test isolates (Figs. 6,7). The highest antifungal activity of this essential oil was observed against DQ086833 (zone of inhibition of $5 \mathrm{~cm} \mathrm{~mm}$ at $2 \%$ concentration) followed by AY264267 (zone of inhibition of $4.5 \mathrm{~cm}$ ). EON completely inhibited the mycelial growth of all FOV isolates at $5 \%$ concentration. The fungitoxic effect of EON persisted even at all concentrations.

\section{Effect of EON on fungal morphology}

As to the effects of the eugenol on the morphology of FOV, it was clearly observed that a reduction in hyphae pigmentation, size and number of conidiospores. Mycelial growth of FOV was inhibited by EON in a concentrationdependent manner. However, eugenol did not inhibit the germination of fungal conidia at all concentrations tested (Fig. 8). Almost of macro- and micro-conidiospores treated with $2 \%$ EON resulted in the leakage of pink-absorbing materials compared with the controls and the release was concentration dependent (Fig. 8c). 
Fig. 2 Triangular phase diagram constructed with water, tween 20 and eugenol oil at different compositions. Nanoemulsion phases of these four mixture systems are encircled in red

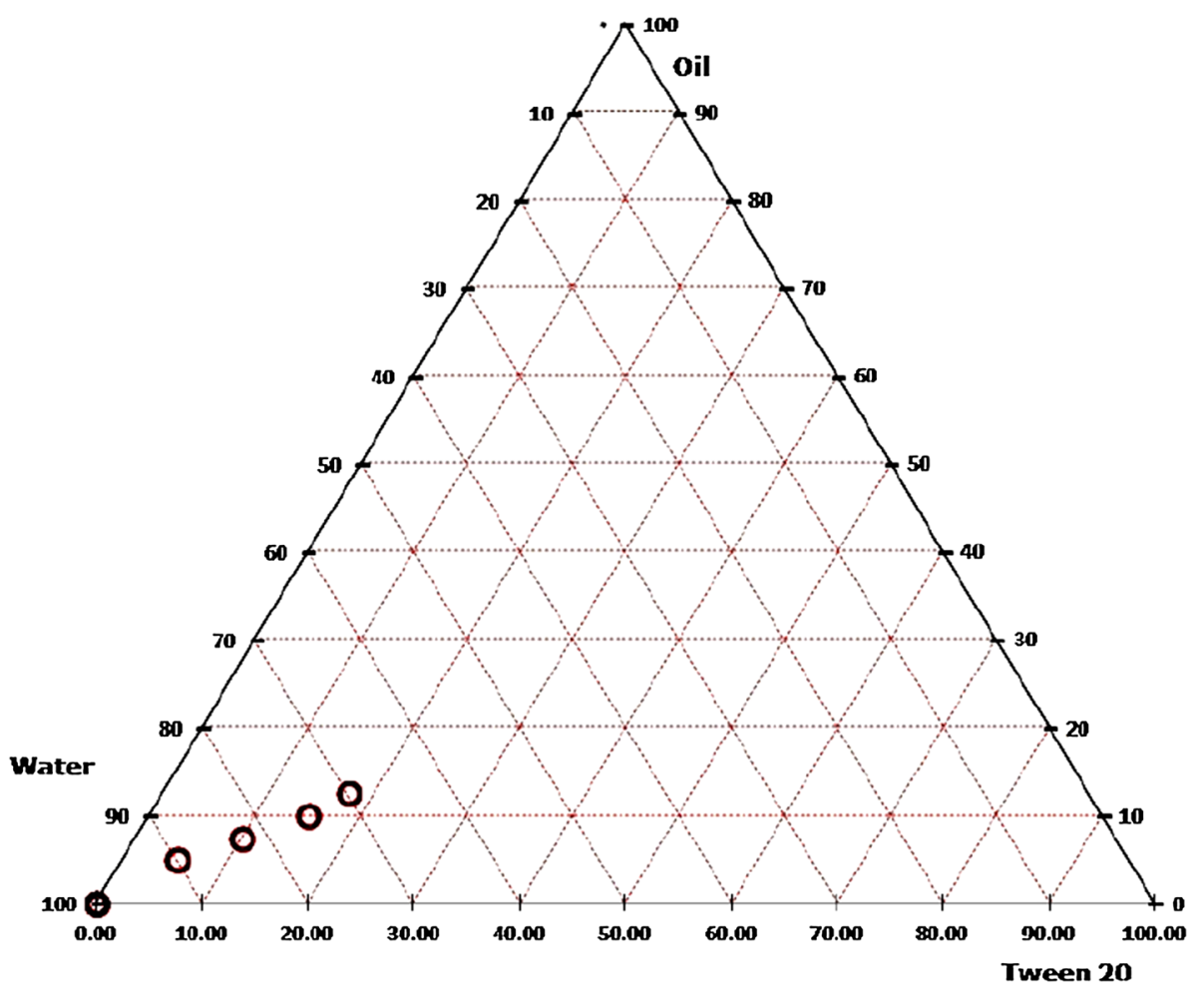

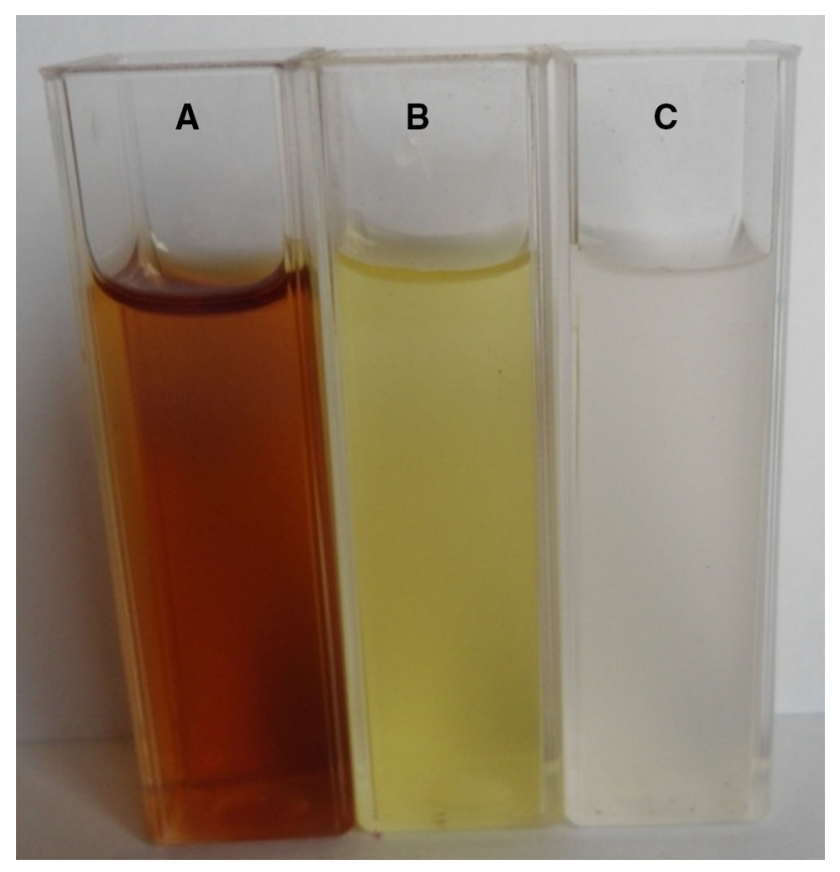

Fig. 3 Macro, (a pale red), micro (b pale yellow) and nano scale (c white) eugenol emulsion

Protein gel-based analysis of FOV isolates treated with EON

SDS-PAGE results of total protein from the FOV isolate before and after treatment with eugenol oil nanoemulsion indicated that the FOV secreted three different proteins

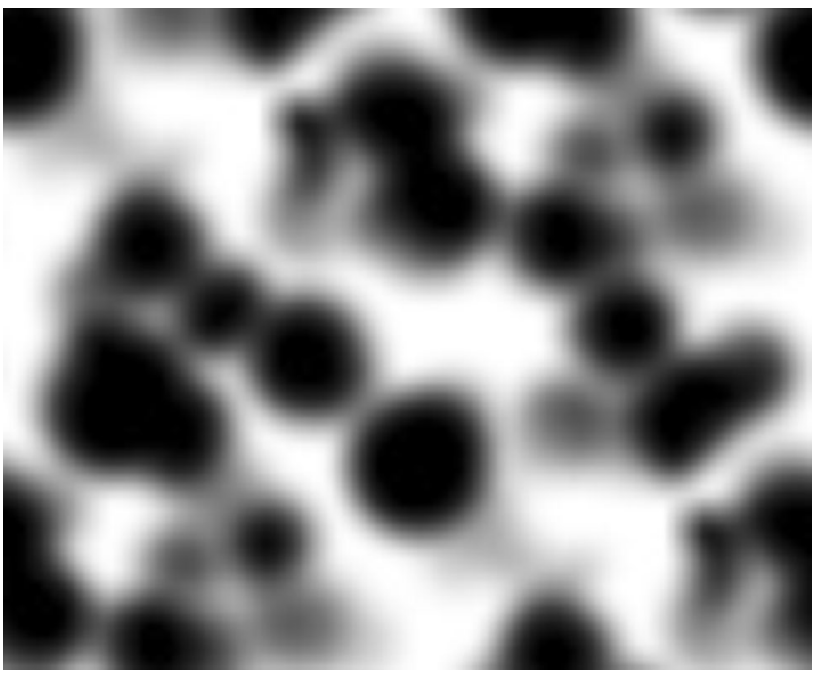

Fig. 4 Transmission electron microscopic image of nano-eugenol oil with 1:6 (v/v) ratio of oil and surfactant

with molecular mass ranging between $50 \mathrm{kDa}, 38 \mathrm{kDa}$, and $19 \mathrm{kDa}$ (Fig. 9). The brightness of 7 reduced bands (about $24 \mathrm{kDa}, 20 \mathrm{kDa}, 18 \mathrm{kDa}, 15 \mathrm{kDa}, 13 \mathrm{kDa}, 7 \mathrm{kDa}$, and $5 \mathrm{kDa}$ ) was distinctly decreased after the exposure of EON. This implies that small molecular proteins of the treated FOV isolate were more easily affected. Thus, FOV isolate in stressful condition with the presence of EON at high concentration could reduce the production of some proteins. 


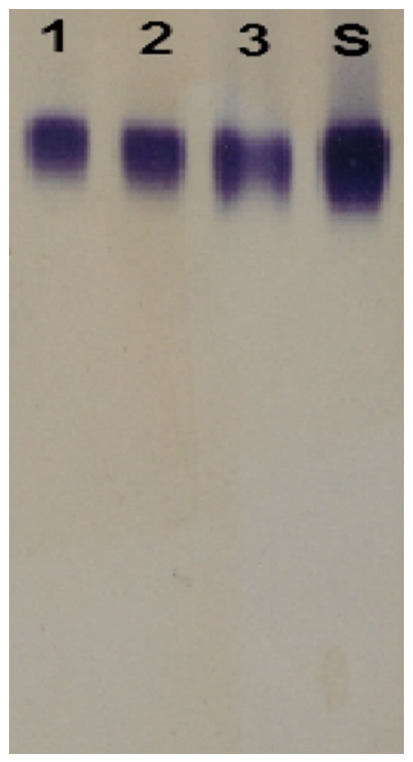

Fig. 5 TLC chromatograms of eugenol oil on silica gel 60-F254 aluminum sheet. Lane 1: $1 \% \mathrm{EON}$, lane 2: $2 \% \mathrm{EON}$, lane 3: $5 \%$ EON, Lane S, eugenol standard

Effects of nano-eugenol oil on incidence of fusarium wilt

ANOVA (Table 1) for Fusarium wilt incidence indicated highly significant $(p=0.000)$ effects for concentration, genotype, and their interaction. Genotype was the most important source of variation as it accounted for $93.18 \%$ of the explained (model) variation in wilt incidence followed by the interaction, while concentration was the least import source of variation. Due to the highly significant interaction $(p=0.000)$ between genotype and concentration, an interaction least significant difference (LSD) was calculated to compare concentration means within each genotype (Table 2). These comparisons showed that the difference in wilt incidence between concentrations and control was not the same for each genotype, that is, the genotypes responded differently to concentrations. For example, the lower concentration $(1 \%)$ was ineffective in controlling the disease on lines 276,269 , and 254 while it was highly effective $(p \leq 0.01)$ the other lines. The higher concentration $(2 \%)$ showed variable effects on wilt incidence depending on the tested genotype. Thus, it caused highly significant $(p \leq 0.01)$ increase in wilt incidence on line 276 and 254, while it had no effect on wilt incidence on line 280. This concentration also showed significant or highly significant decreases in wilt incidence on the remaining lines. Fusarium wilt symptoms on line 276 seedlings treated and untreated with Eugenol oil nanoemulsion are shown in Fig. 10.

\section{Effects of EON on viability of cottonseeds}

In vitro experiments were conducted to evaluate the potential phytotoxic effect of the EON. Concentration, genotype and concentration $\mathrm{x}$ genotype interaction were all highly significant sources of variation in seed germination; however, interaction was the first in importance as a source of variation followed by the concentration, while genotype was the least important source of variation (Table 3).

The concentration was a very highly significant source of variation in radicle length, the genotype was almost a significant source of variation and the interaction was nonsignificant (Table 4). The effects were the first in importance as a source of variation in radicle length, while the concentrations of EON and the interaction were negligible (Table 4).

Due to the significance of concentration $\mathrm{x}$ genotype interaction, an interaction LSD was calculated to compare between concentrations within genotypes (Table 5). These

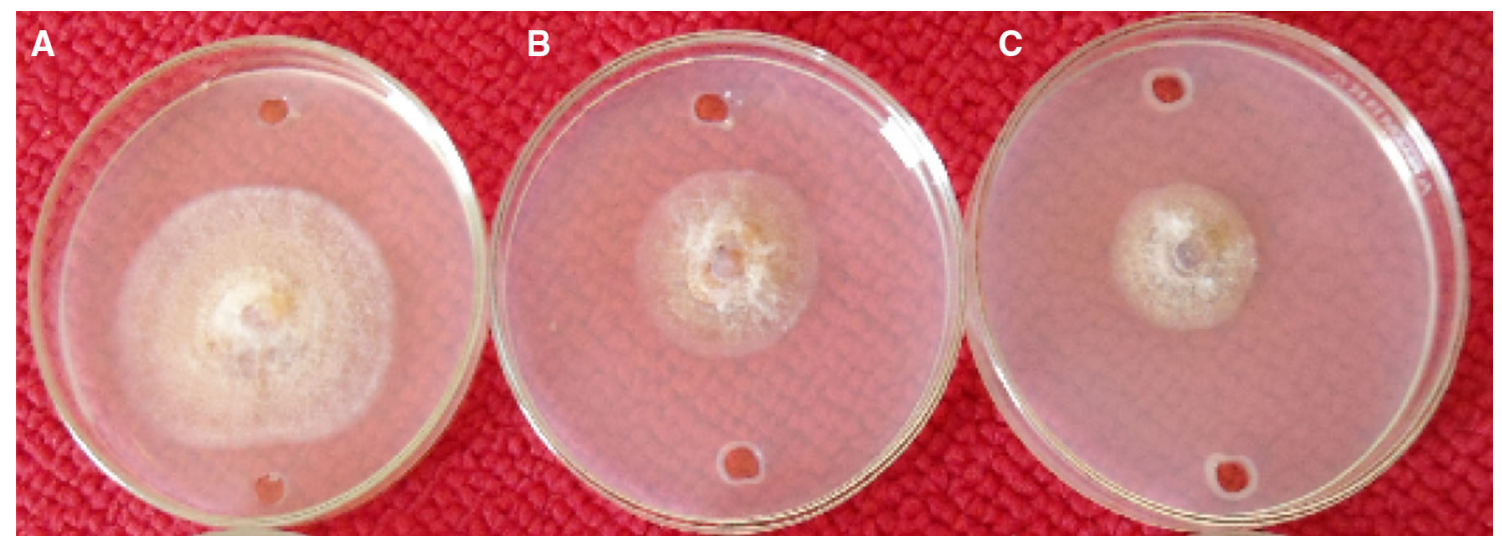

Fig. 6 Effects of agar well double diffusion assay of EON oil treatment at 1 and $2 \%$ on mycelium growth of FOV after 8 days incubation (a: control, b: EON1 \%, c: EON $2 \%$ ) 
Fig. 7 Effect of three EON concentration on zone inhibition of Fusarium oxysporum $\mathrm{f}$. sp. vasinfectum (FOV) isolates

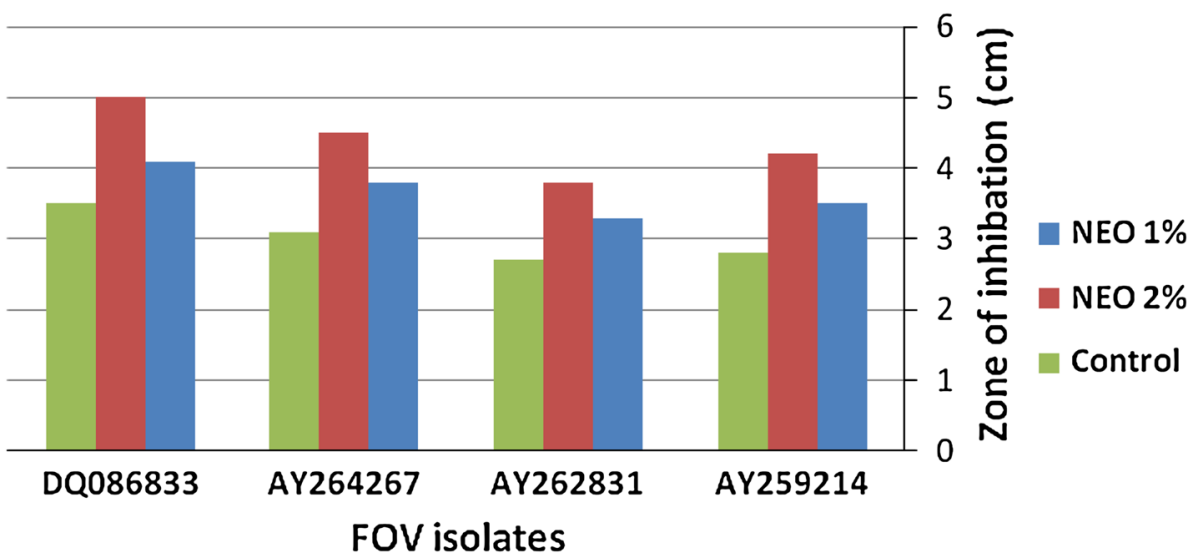

A
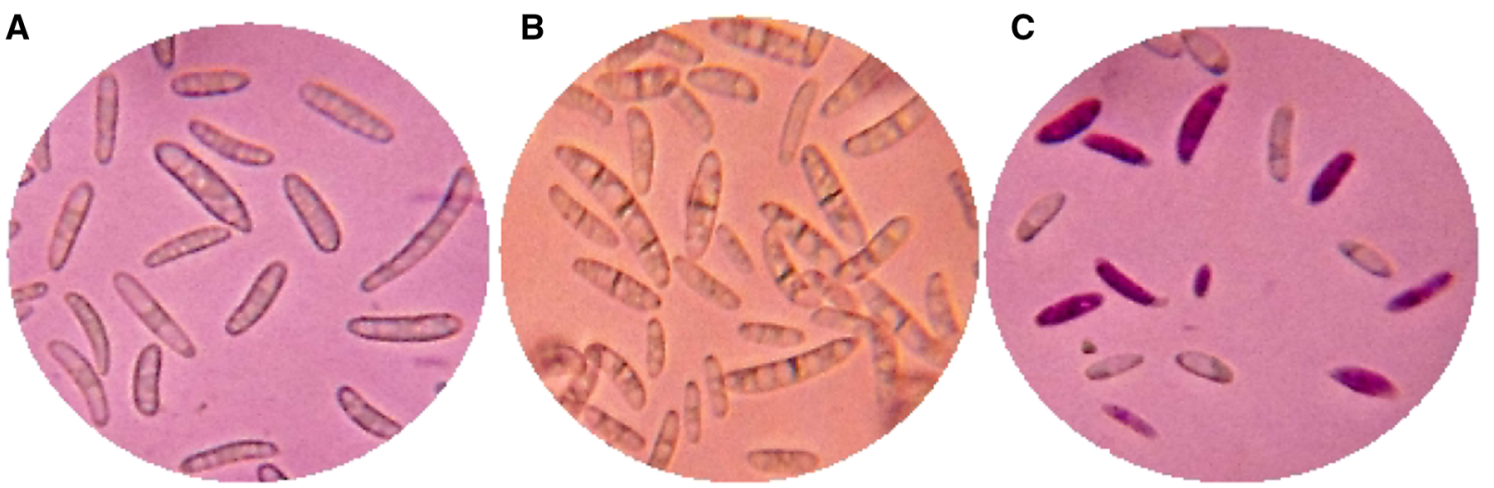

Fig. 8 Light microscope examination of FOV conidiospores grown on PDA with or without EON during 4 days of incubation at $28{ }^{\circ} \mathrm{C}$ $(40 \times$ magnification $)$. a treated macro- and micro-conidiospores with

$1 \%$ EON b untreated macro- and micro-conidiospores c treated macro- and micro-conidiospores with $2 \%$ EON

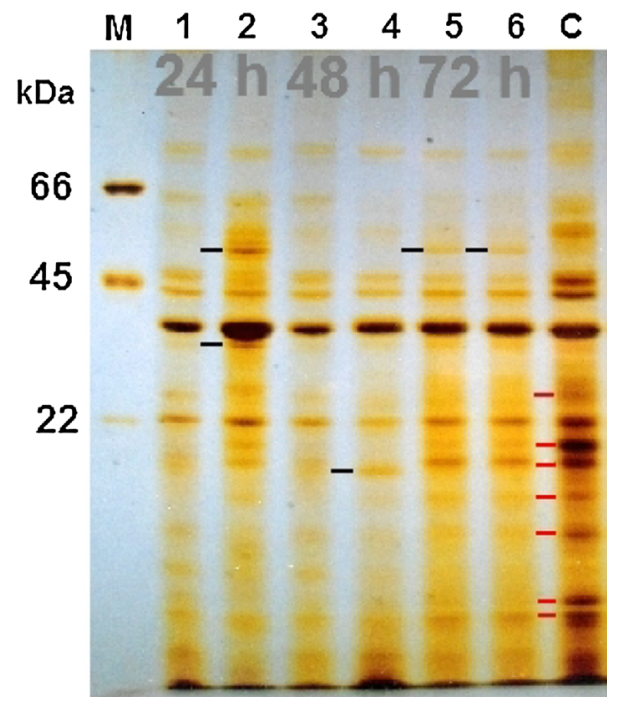

Fig. 9 Ten percentage SDS-PAGE of FOV mats treated with nanoeugenol oil (EON). Lane 1, 3, and 5: (1\% EON). Lane 2, 4, and 6 ( $2 \% \mathrm{EON})$. Lane M contains protein marker (66 kDa, Bovine Serum Albumin), (45 kDa Carbonic Anhydrase), (22 kDa Trypsin Inhibitor). Protein bands in black line (three stimulated band) and bands in red line (seven reduced band) comparisons showed that the effects of concentrations of seed germination varied from one line to another. Thus, the concentration of $1 \%$ significantly reduced seed germination of all the tested lines except for lines 254, 280 and 289. The concentration of $2 \%$ significantly reduced seed germination of lines 276, 277, 207, and 289, while it showed no significant effects on seed germination of the remaining lines. The comparisons also showed that the differences between the two concentrations varied depending on the tested line. Thus, the differences between the two concentrations were significant on lines 276, 269, 207, 270, and 289 , while the differences were nonsignificant on the other lines.

Due to the nonsignificant interaction, LSD was calculated to compare between the general means of genotypes and the general means of concentrations (Table 5). These comparisons showed that the tested concentrations significantly reduced radicle length; however, the difference between the two concentrations was nonsignificant line 270 showed the shortest radicle, while lines 267 and 280 showed the longest radicle. 
Table 1 Analysis of variance of effects of nano-eugenol oil concentrations, cotton genotypes, and their interaction on incidence of fusarium wilt

\begin{tabular}{|c|c|c|c|c|c|}
\hline Source of variation & D. F & M. S & $F$ value & $\mathrm{P}>\mathrm{F}$ & $\mathrm{RC}^{\mathrm{a}}$ \\
\hline Replication & 4 & 186.163 & 1.4706 & 0.2156 & \\
\hline Concentration (C) & 2 & $6,359.829$ & 50.2409 & 0.0000 & 1.98 \\
\hline Genotype(G) & 9 & $66,642.876$ & 52.4769 & 0.0000 & 93.18 \\
\hline $\mathrm{C} \times \mathrm{G}$ & 18 & $1,689.629$ & 13.3476 & 0.0000 & 4.37 \\
\hline Error & 116 & 126.587 & & & \\
\hline
\end{tabular}

a Relative contribution (RC) to variation in wilt incidence calculated as percentage of sum of square of the explained (model) variation

Table 2 Effect of nano-eugenol oil concentrations on incidence of Fusarium wilt cotton on 10 cotton genotypes

\begin{tabular}{llcr}
\hline Genotype & \multicolumn{3}{l}{ Incidence (\%) of Fusarium wilt } \\
\cline { 2 - 4 } & \multicolumn{2}{l}{ Nano-eugenol oil concentrations $(\%)$} \\
\cline { 2 - 4 } & Control & $1 \%$ & $2 \%$ \\
\hline Line 276 & 2.00 & 6.5 & 33.09 \\
Line 269 & 29.17 & 15.67 & 11.94 \\
Line 277 & 54.45 & 21.11 & 14.44 \\
Line 207 & 43.36 & 18.94 & 13.22 \\
Line 270 & 30.55 & 16.67 & 12.94 \\
Line 268 & 40.00 & 0.00 & 0.00 \\
Line 267 & 27.10 & 0.00 & 2.50 \\
Line 254 & 16.94 & 9.44 & 61.79 \\
Line 280 & 81.67 & 41.94 & 87.50 \\
Line 289 & 93.56 & 67.61 & 31.43 \\
\hline
\end{tabular}

LSD for genotype $\mathrm{x}$ concentration interaction $=18.62(p \leq 0.01)$ or $14.09(p \leq 0.05)$
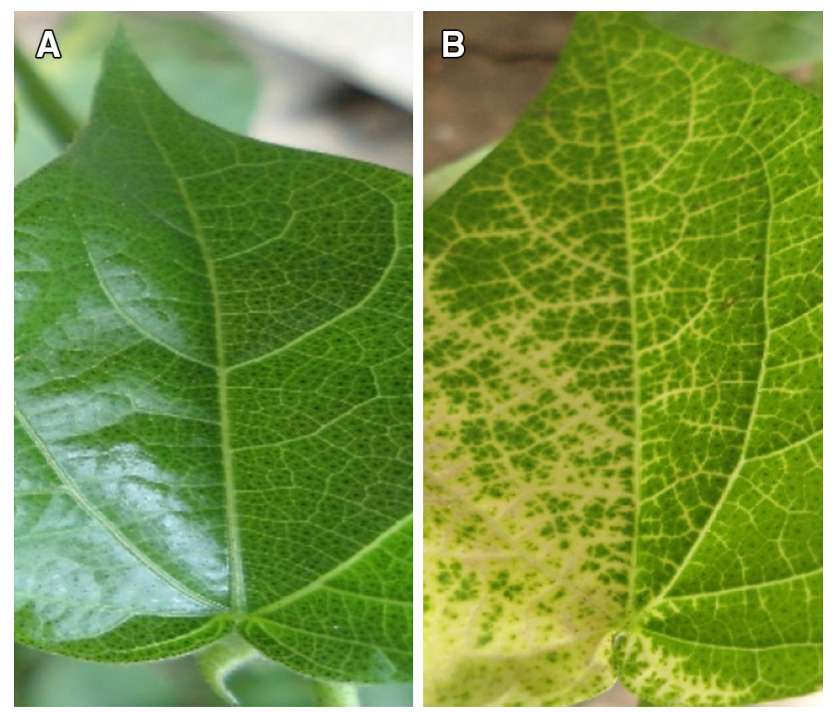

Fig. 10 Effectiveness of EON in controlling Fusarium wilt under greenhouse conditions. a Cotton seedlings treated with eugenol oil nanoemulsion b, Severely affected seedlings after planting in artificially infested soil in a greenhouse test (untreated cottonseed) (Vein discoloration began at the margin of cotyledonary leaf)
Table 3 Analysis of variance of effects of nano-eugenol oil concentrations, cotton genotypes, and their interaction on seed germination

\begin{tabular}{lccrrr}
\hline Source of variation & D. F & M. S & F value & P $>$ F & RC $^{\mathrm{a}}$ \\
\hline Replication & 2 & 217.778 & 2.027 & 0.141 & \\
Concentration (C) & 2 & $8,431.11$ & 78.478 & 0.000 & 41.57 \\
Genotype(G) & 9 & $1,061.235$ & 9.878 & 0.000 & 23.55 \\
C $\times$ G & 18 & $7,610.975$ & 7.093 & 0.000 & 33.81 \\
Error & 58 & 107.433 & & & \\
\hline
\end{tabular}

${ }^{a}$ Relative contribution (RC) to variation in seed germination calculated as percentage of sum of square of the explained (model) variation

Table 4 Analysis of variance of effects of nano-eugenol oil concentrations, cotton genotypes, and their interaction on radicle lengths $(\mathrm{cm})$

\begin{tabular}{lrrrrr}
\hline Source of variation & D. F & \multicolumn{1}{l}{ M. S } & F value & P > F & RC \\
\hline Replication & 4 & 23.245 & 7.868 & 0.000 & \\
Concentration (C) & 2 & 523.301 & 177.132 & 0.000 & 84.72 \\
Genotype(G) & 9 & 4.740 & 1.996 & 0.046 & 3.45 \\
C x G & 18 & 2.954 & 1.605 & 0.070 & 4.30 \\
Error & 116 & & & & \\
\hline
\end{tabular}

${ }^{a}$ Relative contribution (RC) to variation in radicle lengths calculated as percentage of sum of square of the explained (model) variation

The lack of significant correlation between each of seed viability and disease incidence may suggest that the two concentrations of nano-eugenol oil affected disease incidence through the pathogen and not through the host (Table 6).

\section{Discussion}

An eco-friendly fungicide is under development that uses nanomaterials to release its pathogen killing properties only when it is inside the targeted plant pathogens (Choudhury et al. 2010; Abd-Elsalam 2012; Rai and Ingle 2012). Eugenol has antimicrobial activity against a variety 
Table 5 Effect of nano-eugenol oil concentrations, cotton genotypes on seed germination $(\%)$ and radicle length $(\mathrm{cm})$

\begin{tabular}{|c|c|c|c|c|c|c|c|c|}
\hline \multirow[t]{3}{*}{ Genotype } & \multicolumn{8}{|c|}{ Eugenol oil nanoemulsion concentrations (\%) } \\
\hline & \multicolumn{4}{|c|}{ Seed germination $(\%)$} & \multicolumn{4}{|c|}{ Radicle length $(\mathrm{cm})$} \\
\hline & 1 & 2 & 0 & Mean & 1 & 2 & 0 & Mean \\
\hline Line 276 & 46.67 & 66.67 & 86.67 & 66.67 & 0.40 & 0.80 & 6.80 & 2.67 \\
\hline Line 269 & 46.67 & 93.67 & 100.00 & 80.00 & 0.10 & 0.80 & 7.20 & 2.70 \\
\hline Line 277 & 46.67 & 53.33 & 100.00 & 66.67 & 0.70 & 1.40 & 5.34 & 2.48 \\
\hline Line 207 & 40.00 & 66.67 & 100.00 & 68.89 & 0.06 & 0.60 & 8.00 & 2.89 \\
\hline Line 270 & 46.67 & 73.33 & 100.00 & 73.33 & 0.30 & 0.00 & 4.90 & 1.73 \\
\hline Line 268 & 80.00 & 73.33 & 100.00 & 84.44 & 1.30 & 0.02 & 5.16 & 2.16 \\
\hline Line 267 & 80.00 & 73.33 & 100.00 & 84.44 & 0.72 & 4.00 & 6.80 & 3.84 \\
\hline Line 254 & 86.67 & 93.33 & 100.00 & 93.33 & 0.06 & 2.00 & 6.54 & 2.87 \\
\hline Line 280 & 93.33 & 100.00 & 100.00 & 97.78 & 2.00 & 0.60 & 7.74 & 3.45 \\
\hline Line 289 & 100.00 & 46.67 & 100.00 & 82.22 & 0.64 & 0.00 & 5.70 & 2.11 \\
\hline Mean & 66.67 & 74.00 & 98.67 & & 0.63 & 1.02 & 6.42 & \\
\hline \multicolumn{5}{|c|}{ LSD $(p \leq 0.05)$ for genotype $\mathrm{x}$ concentration interaction $=16.75$} & \multicolumn{4}{|c|}{ LSD $(p \leq 0.05)$ for concentration $=0.68$} \\
\hline
\end{tabular}

Table 6 Correlation between disease incidence (DI) and cotton seeds germination traits treated with two concentrations of nano-eugenol oil

\begin{tabular}{lll}
\hline & \multicolumn{2}{l}{ Disease incidence $^{\mathrm{b}}$} \\
\cline { 2 - 3 } & \multicolumn{2}{l}{ Eugenol oil nanoemulsion concentrations $(\%)$} \\
\hline Variable $^{\mathrm{a}}$ & 1 & 2 \\
seed germination & $-0.486^{\mathrm{c}}$ & 0.280 \\
radicle lengths & -0.391 & 0.435 \\
\hline
\end{tabular}

${ }^{a}$ The variables were determined in in vitro

b Disease Incidence was determined in in vivo

${ }^{c}$ All linear correlation coefficients are nonsignificant $(p>0.05)$, $N=10$

of food-borne (Ghosh et al. 2014), of plant pathogens (Wang et al. 2010), and mycotoxigenic fungi (Morcia et al. 2012). On the other hand, little attention has been paid to its antifungal activity against Fusarium wilt in cotton. In the present study, nano-eugenol oil was prepared and characterized for particle size, transmission electron microscope. The antifungal activities of the synthesized EONs were evaluated under in vitro and in vivo models using ten susceptible cotton genotypes.

The phase diagram results confirmed that four nanoemulsions were prepared using diverse percentages of water, eugenol oil and tween 20. Increased solubility of eugenol oil components in the aqueous phase in the presence of surfactants may lead to enhanced interactions of antimicrobials with microorganisms (Shakeel et al. 2010).

Nanoemulsions are kinetically stable up to more than 1-month kept at room temperature and are formed from a particular concentration of oil phase, surfactant and water, with no phase separation. Particle size of nanoemulsion was one of the most important properties. The nanoemulsion droplets were found to have a Z-average diameter of $80 \mathrm{~nm}$.

Stirring is known to reduce droplet size in an oil-inwater emulsion (Sajjadi et al. 2002). The fabrication of nanoemulsion with lesser droplet size in the presence of double bonds in the nonpolar chain of non-ionic surfactants was evaluated by Dai et al. (1997).

The TEM micrograph showed that the EON was spherical in shape and moderately mono or di-dispersed and was in the range of 50-110 nm. TLC analysis can be used to identify the bioactive components present in the tested EON concentrations compared with standard eugenol that served as positive control. TLC analysis showed that Eugenol was present as a main component in the three EON tested concentration, as the colored zone showed the same $R_{\mathrm{f}}$ value comparable with eugenol standard. Similar fractionation was performed using TLC analysis to identify the active antifungal components in clove oil (Park et al. 2007; Rana et al. 2011).

The EON exhibited varying antifungal activity against the various tested isolates. The highest antifungal activity of this essential oil was observed against DQ086833 (zone of inhibition of $5 \mathrm{~cm} \mathrm{~mm}$ at $2 \%$ concentration) followed by AY264267 with zone of inhibition of $4.5 \mathrm{~cm}$. The phenolic component of eugenol showed high level of toxicity against plant pathogenic fungi (Morcia et al. 2012; Matan et al. 2014). There are several possibilities for antifungal mechanism of EOs described by researchers but the exact mechanism has not been verified. For bioactivity, the EOs pass through the cell wall and cytoplasmic 
membrane (Bakkali et al. 2008). These results allowed us to hypothesize about an action of eugenol may inactivate essential enzymes, react with the cell membrane or disturb genetic material functionality (Woo et al. 2009). Eugenol acts on cell membrane by a mechanism that seems to involve the inhibition of ergosterol biosynthesis (de Oliveira et al. 2013). Eugenol oil nanoemulsion inhibited not only radial growth, but also sporulation and pigmentation of the pathogen. The mycelial tips were also swelled, branched and distorted. Several authors have demonstrated that eugenol alone could reduce the growth rate of mold and also reduce mycotoxins produced by mold (Amiri et al. 2008). Eugenol, known to be a lipophilic compound, can enter between the fatty acid chains that make up the membrane lipid bilayers, thus altering the fluidity and permeability of cell membranes (Gill and Holley 2006; Braga et al. 2007). These findings were supported by the intensive staining of eugenol-treated conidia of FOV (Fig. 9c).

When an microorganism is exposed to outer stress in forms of different bioactive compounds this could cause effects on the genomes which in turn regulates the proteins [42] (Bodson-Kulakowska et al. 2007). SDS-PAGE analysis was performed to verify whether there were any differences in protein profiles between treated and untreated FOV exposed to the EON concentration. Some novel protein bands appeared in the protein profiles of coated fungal cells; however, some protein bands disappeared.

In this study, we have evaluated antifungal potential of nano-eugenol oil (EON) against in Fusarium wilt of cotton in pot experiments. ANOVA for Fusarium wilt incidence indicated highly significant $(p=0.000)$ effects for concentration, genotype, and their interaction. The difference in wilt incidence between concentrations and control was not the same for each genotype, that is, the genotypes responded differently to concentrations.

To evaluate the potential toxic effect of EON molecules against cotton plants, the viability was tested on ten cotton genotype. RC of each source of variation showed that the oil concentration is the main factor affecting model variation. Our findings are in harmony with the obtained results by Morcia et al. (2012). When 1, 5, and $10 \%$ aqueous emulsions of clove extracts were applied for control Fusarium wilt disease in muskmelon, the $10 \%$ formulation caused stunting and other phytotoxic symptoms (Bowers and Locke 2000).

\section{In conclusion}

The present work aims to formulate and characterize biobased oil in water nanoemulsion. The synthesized nanoemulsion was characterized by particle size analyzer, stability test, TEM and thin layer chromatography. Antifungal potential of Eugenol oil nanoemulsion against in Fusarium wilt of cotton was assessed in in vitro, and in vivo tests. Our studies confirmed the inhibitory effect of EON on growth of FOV. TLC assay confirmed the presence of eugenol as an active antifungal component in all tested concentration. Total protein SDS-PAGE assay further investigated the molecular weight of the decreased and stimulated proteins. Phytotoxic effects were determined on cottonseed treated with high concentration of eugenol oil nanoemulsion. Additional study needed to understand toxicity mechanisms in plant pathogens and higher plant species. The strong antagonistic activity against FOV recommends that EON could be used as an efficient nanofungicide in plant disease control.

Acknowledgments Unit of Excellence in Nano-Molecular Plant Pathology Research, Agricultural Research Center (ARC), Egypt is appreciated for funding this study. Also, this work was partially funded by the Science and Technology Development Fund (STDF), Egypt, (STDF), Egypt, (STDF-STF program, Grant no. 4552 to Kamel Abd-Elsalam).

Open Access This article is distributed under the terms of the Creative Commons Attribution License which permits any use, distribution, and reproduction in any medium, provided the original author(s) and the source are credited.

\section{References}

Abd-Elsalam KA (2012) Nanoplatforms for plant pathogenic fungi management. Fungal Genome Biol 2012(2):2

Abd-Elsalam KA, Omar MR, Asran-Amal A, Mansour MT, Aly AA (2014) Evaluation of a cotton germplasm collection against Fusarium wilt race 3 isolates from Egypt. Trop Plant Pathol 39:95-103

Amiri A, Dugas R, Pichot AL, Bompeix G (2008) In vitro and in vitro activity of eugenol oil (Eugenia caryophylata) against four important postharvest apple pathogens. Int $\mathrm{J}$ Food Microbiol 126:13-19

Anonymous (2000) Internationale Vorschriften für die Prüfung von Saatgut 1999: Seed Sci Technol 27: Suppl

Bakkali F, Averbeck S, Averbeck D, Waomar M (2008) Biological effects of essential oils-a review. Food Chem Toxicol 46:446-475

Bodson-Kulakowska A, Bierczynska-Krzysik A, Dylag T, Drabik A, Suder P, Noga M, Jarzebinska J, Silberring J (2007) Methods for samples preparation in proteomic research. J Chromatogr B 849:1-31

Bowers JH, Locke JC (2000) Effect of botanical extracts on the population density of Fusarium oxysporum in soil and control of fusarium wilt in the greenhouse. Plant Dis 84:300-305

Braga PC, Sasso MD, Culici M, Alfieri M (2007) Eugenol and thymol, alone or in combination, induce morphological alterations in the envelope of Candida albicans. Fitoterapia 78:396-400

Brent KJ, Hollomon DW (1998) Fungicide Resistance: The Assessment of Risk, pp. 48. FRAC Monograph No. 2, Global Protection Federation 
Choudhury SR, Nair KK, Kumar R, Gogoi R, Srivastava C, Gopal M, Subhramanyam BS, Devakumar C, Goswami A (2010) Nanosulfur, A potent fungicide against food pathogen, Aspergillus niger. AIP Conf Proc 1276:154-157

Daferera DJ, Ziogas BN, Polissiou MG (2003) The effectiveness of plant essential oils on the growth of Botrytis cinerea, Fusarium spp. and Clavibacter michiganensis subsp. michiganensis. Crop Prot 22:39-44

Dai L, Li W, Hou X (1997) Effect of the molecular structure of mixed nonionic surfactants on the temperature of miniemulsion formation. Colloids Surf A Physicochem Eng Aspects 125:27-32

de Oliveira Pereira F, Mendes JM, de Oliveira Lima E (2013) Investigation on mechanism of antifungal activity of eugenol against Trichophyton rubrum. Med Mycol 51:507-513

Fahmy T (1927) The Fusarium wilt disease of cotton and its control. Phytopathology 17:749-767

Feng W, Zheng X (2007) Essential oils to control Alternaria alternate in vitro and in vivo. Food Control 18:1126-1130

Ghosh V, Mukherjee A, Chandrasekaran N (2014) Eugenol-loaded antimicrobial nanoemulsion preserves fruit juice against, microbial spoilage. Colloids Surf B Biointerfaces 114:392-397

Gill AO, Holley RA (2006) Inhibition of membrane bound ATPase of Escherichia coli and Listeria monocytogenes by plant oil aromatics. Int J Food Microbiol 111:170-174

Gogoi R, Dureja PS, Pradeep K (2009) Nanoformulations-A safer and effective option for agrochemicals. Indian Farming 59:7-12

Hamouda T, Myc A, Donovan B, Shih AY, Reuter JD, Baker JR (2001) A novel surfactant nanoemulsion with a unique nonirritant topical antimicrobial activity against bacteria, enveloped viruses and fungi. Microbiol Res 156:1-7

Hillocks RJ (1992) Fusarium wilt. In: Hillocks RJ (ed) Cotton diseases. Redwood Press Ltd, Melksham UK, pp 127-160

Hostettmann K (1999) Strategy for the biological evaluation of plant extracts. Pure App. Chem. 70:1109-1113

Kah M, Beulke S, Tiede K, Hofmann T (2013) Nano-pesticides: state of knowledge, environmental fate and exposure modelling. Crit Rev Environ Sci Technol 43:1823-1867

Laemmli UK (1970) Cleavage of structural proteins during the assembly of the bacteriophage T4. Nature 227:680-685

Li ZZ, Chen JF, Liu F, Liu AQ, Wang Q, Sun HY, Wen LX (2007) Study of UV-shielding properties of novel porous hollow silica nanoparticle carriers for avermectin. Pest Manag Sci 63:241-246

Matan N, Saengkrajang W, Matan N (2011) Antifungal activities of essential oils applied by dip-treatment on areca palm (Areca catechu) leaf sheath and persistence of potency upon storage. Int Biodeterior Biodegradation 65:212-216

Matan N, Nisoa M, Matanc N, Aewsiri T (2014) Effect of cold atmospheric plasma on antifungal activities of clove oil and eugenol against molds on areca palm (Areca catechu) leaf sheath. Int Biodeterior Biodegradation 86:196-201

Morcia C, Malnati M, Terzi V (2012) In vitro antifungal activity of terpinen-4-ol, eugenol, carvone, 1,8-ciEONle (eucalyptol) and thymol against mycotoxigenic plant pathogens. Food Addit Contam Part A 29:415-422
Myc A, Vanhecke T, Landers JJ, Hamouda T, Baker JR (2002) The fungicidal activity of novel nanoemulsion (X8W60PC) against clinically important yeast and filamentous fungi. Mycopathologia 155:195-201

Park MJ, Gwak KS, Yang I, Choi WS, Jo HJ, Chang JW, Jeung EB, Choi IG (2007) Antifungal activities of the essential oils in Syzygium aromaticum (L.) Merr. Et Perry and Leptospermum petersonii Bailey and their constituents against various dermatophytes. The J Microbiol 45:460-465

Perez C, Paul M, Bazerque P (1990) Antibiotic assay by agar-well diffusion method. Acta Bio Med Exp. 15:113-115

Pérez-de-Luque A, Rubiales D (2009) Nanotechnology for parasitic plant control. Pest Manag Sci 65:540-545

Pinto E, Vale-Silva L, Cavaleiro C, Salgueiro L (2009) Antifungal activity of the clove essential oil from Syzygium aromaticum on Candida, Aspergillus and dermatophyte species. J Med Microbiol 58:1454-1462

Rabilloud TG, Carpentier A, Tarroux P (1988) Improvement and simplification of low-background silver staining of proteins by using sodium dithionite. Electrophoresis 6:288-291

Rai M, Ingle A (2012) Role of nanotechnology in agriculture with special reference to management of insect pests. Appl Microbiol Biotechnol 94:287-293

Rana IS, Rana AS, Rajak RC (2011) Evaluation of antifungal activity in essential oil of the Syzygium aromaticum (1.) by extraction, purification and analysis of its main component eugenol. Brazil J Microbiol 42:1269-1277

Sajjadi S, Zerfa M, Brooks WB (2002) Dynamic behaviour of drops in oil/water/oil dispersions. Chem Eng Sc 57:663-675

Shafiq S, Shakeel F (2010) Stability and self-nanoemulsification efficiency of ramipril nanoemulsion containing labrasol and plurol oleique. Clin Res Regul Aff 27:7-12

Shakeel F, Ramadan W, Faisal MS, Rizwan M, Faiyazuddin M, Mustafa G, Shafiq S (2010) Transdermal and topical delivery of anti-inflammatory agents using nanoemulsion/microemulsion: an updated review. Curr Nanosci 6:184-198

Tohidfar M, Hossaini R, Shokhandan-Bashir Meisam T (2012) Enhanced resistance to verticillium dahlia in transgenic cotton expressing an endochitinase gene from Phaseolus vulgaris. Czech J Genet Plant Breed 48:33-41

Wang L, Li Z, Zhang G, Dong J, Eastoe J (2007) Oil-in-water nanoemulsions for pesticide formulations. J Colloid Interface Sci 314:230-235

Wang C, Zhang J, Chen H, Fan Y, Shi Z (2010) Antifungal activity of eugenol against Botrytis cinerea. Trop Plant Pathol 35:137-143

Watkins QM (1981) Compendium of cotton diseases. American Phytopathological Society, St. Paul Minnesota

Woo KS, Kim KS, Lamsal K, Kim YJ, Kim SB, Jung M, Sim SJ, Kim HS, Chang SJ, Kim JK, Lee YS (2009) An in vitro study of the antifungal effect of silver nanoparticles on oak wilt pathogen Raffaelea sp. J Microbiol Biotechnol 19:760-764 